\title{
Comparability and reproducibility of apex cardiogram recorded with six different transducer systems ${ }^{1}$
}

\author{
JOS L. H. WILLEMS, BOUDEWIJN DENEF, HUGO KESTELOOT, AND \\ HILAIRE DE GEEST
}

From the Divisions of Medical Informatics and Cardiology, University of Leuven, Belgium

SUMMARY A comparison was made in 7 dogs of the results obtained by 6 different apex cardiographic transducers applied before, during, and after controlled infusion of angiotensin and isoprenaline.

The electrocardiogram, internal phonocardiogram, aortic and left ventricular pressure using a Telco micromanometer, and apex cardiogram were recorded simultaneously on magnetic tape and paper. Digital computer techniques were used to derive various measurements. The comparison of the 6 transducer systems was made especially with respect to measurements derived from the normalised derivative, calculated using total as well as developed pressure or displacement.

Measurements derived from left ventricular pressure were very reproducible. Differences in results of 'contractility' indices varied between 0.5 and 1.9 per cent. Indices from the apex cardiogram using 6 different transducer systems showed variations up to 20 per cent, with mean values varying between 3.2 and $8 \cdot 1$ per cent. There was a systematic deviation for one transducer system, which was responsible for a significant part of the observed variability.

It may be concluded that in order to assure maximal reproducibility, technical characteristics of the apex cardiograph transducer should be taken into account and an optimal recording technique should be used.

Reproducibility of results is a prerequisite for any method to have scientific value. Many authors have noted that certain morphological features of the apex cardiogram are consistent, when recordings are made at different intervals in time (Hartman and Snellen, 1960; Benchimol and Dimond, 1963; Tavel, 1967; Wayne, 1970; Craige, 1973). However, few systematic studies have been performed on the reproducibility of the apex cardiogram. In none has the apex cardiogram been recorded with different transducer systems (Ginn et al., 1967; Gleichmann, 1968; Motomura et al., 1973; Willems, 1973; Denef et al., 1975; Dübel et al., 1975).

In the present study reproducibility of the apex cardiogram has been tested under well-controlled laboratory conditions. Our objective was to examine the variability resulting from differences in physical characteristics of various transducer systems. A comparison was made of results obtained by 6 different apex cardiographic transducers, applied

\footnotetext{
${ }^{1}$ This work was supported by a grant of the research organisation NFWO of the Belgian Government

Received for publication 26 June 1978
}

consecutively, before, during, and after controlled infusion of angiotensin and isoprenaline in 7 dogs. Studies were made particularly of measurements derived from the normalised apex cardiogram derivative, since in recent years increased attention has been given to these measurements in the noninvasive assessment of left ventricular function (Reale, 1967; Gleichmann, 1968; Fincker et al., 1971; Mirsky et al., 1972; Vetter et al., 1972; Denef et al., 1973; Willems, 1973; Denef et al., 1975; Willems et al., 1975).

\section{Methods}

MATERIAL AND RECORDING TECHNIQUE The experiments were performed in 7 dogs weighing 27 to $32 \mathrm{~kg}$ and anaesthetised by subcutaneous adminstration of a combination of fluanisone $(4 \mathrm{mg} / \mathrm{kg})$ and fentanyl base $(0 \cdot 1 \mathrm{mg} / \mathrm{kg})$ (Hypnorm, Philips-Duphar) followed 30 minutes later by the intravenous injection of sodium pentobarbitone (13 $\mathrm{mg} / \mathrm{kg}$ ), with repeat injections when needed. Artificial positive pressure respiration was instituted through a tracheal cannula by means of a 
Bird respirator and ventilated with a mixture of room-air $(60 \%)$ and oxygen $(40 \%)$.

The apex cardiogram was recorded in the left recumbent position and in expiratory apnoea. Three of the apex cardiograph pick-ups were pressure- and 3 were displacement-measuring devices. Application pressure could be assessed with the fluid pressure-but not with the displacementtransducer systems. All pulse transducers were held by hand at the point of maximal impulse and the recordings were made under oscilloscopic control by the same observer.

\section{MEASUREMENT SYSTEMS}

Essentially two different methods exist to record the apex cardiogram. In displacement apex cardiography free movement of the apical impulse is recorded in relation to the rim of the recording device or to a fixed point in space. In pressure apex cardiography a counter pressure is applied on the thoracic wall and transducer systems are used with a rigid sensing apparatus, so that displacement is as small as possible.

The transducer systems used in this study were the following:

(1) A fluid-filled, calibrated pressure measuring system, with a membrane diameter of $8 \mathrm{~mm}$ (Wesseling and Van Vollenhoven, 1969; Willems et al., 1971a, 1972; Denef et al., 1973; Willems, 1973; van de Werf et al., 1976).

(2) A Marey capsule, connected by plastic tubing (25 cm long and $4 \mathrm{~mm}$ internal diameter) and air transmission to a sensitive Elema EMT 42 pressure transducer (Elema-Schönander, Stockholm) (Kesteloot et al., 1969; Willems, 1973).

(3) The 'conventional' Marey system consisting of a Marey capsule coupled to a piezoelectric microphone (Kesteloot et al., 1969).

(4) A new quantitative displacement measuring system, built in an open ended pick-up capsule (Elema-Schönander, Stockholm) (Nillsson and Thulesius, 1973; Denef et al., 1975).

(5) Same transducer system as no. 1, with a membrane of $6 \mathrm{~mm}$ (Willems, 1973; Denef et al., 1973).

(6) A variable inductance pick-up (Telco, Paris) described by Tricot et al. (1966). This contacting transducer is in fact a modified micromanometer with a rigid sensing head.

Transducer systems 1,2, and 5 are experimental systems developed and tested in our institution. Systems 3, 4, and 6 are commercially available and used in continental Europe and to some extent also in the USA.

The air-coupled crystal microphone systems (systems 3 and 4) had a time-constant, respectively, of 2.5 and 4 seconds. The time constant of the others-was infinite. Response characteristics for high frequencies were variable and have been published previously for all but one system (Tricot $e t$ al., 1966; Kesteloot et al., 1969; Wesseling and Van Vollenhoven, 1969; Willems et al., 1971a, b, 1972; Denef et al., 1973; Nillsson and Thulesius, 1973; Willems, 1973; Denef et al., 1975; Willems et al., 1975; van de Werf et al., 1976).

Pick-up number 1 has been tested by Wesseling and Van Vollenhoven (1969) using a vibrator and the step technique. The response was found to be linear between 0 and $15 \mathrm{~Hz}$. At $20 \mathrm{~Hz}$, a 15 per cent increase in response was noted and the resonance frequency was at $60 \mathrm{~Hz}$. The damping coefficient was 0.075 , which points to an underdamped system, as is often the case with fluid-filled cathetermanometer systems (Wesseling and Van Vollenhoven, 1969; Willems, 1973). The DC Marey system has a flat response from 0 to over $100 \mathrm{~Hz}$ (Kesteloot et al., 1969). The output of pick-up number 3 was linear between $0.05 \mathrm{~Hz}(-3 \mathrm{db}$ point) and $50 \mathrm{~Hz}(10 \%$ overshoot) (Kesteloot et al., 1969). The upper and lower - 3db point attenuation limits of the unfiltered output of transducer number 4, used in the present study, are at, respectively, $1000 \mathrm{~Hz}$ and $0.04 \mathrm{~Hz}$ (Nillsson and Thulesius, 1973; Denef et al., 1975). The resonance frequency of the water-filled pulse transducer with a membrane of $6 \mathrm{~mm}$ lies at $40 \mathrm{~Hz}$ (A. Aubert and J. Joossens, unpublished findings), whereas the inductance pick-up has a flat response between 0 and $1000 \mathrm{~Hz}$ (Tricot et al., 1966).

\section{RECORDING PROCEDURES}

The 6 transducers were applied in a semirandom order, first during basal conditions, next 15 minutes after a constant infusion by means of a Harvard pump of a low dosage of isoprenaline (0.022 \pm $0.011 \mathrm{gamma} / \mathrm{kg}$ per min). Thereafter a return to the basal state was allowed during \pm 15 minutes, after which 6 more control recordings were made. Finally angiotensin was given at a rate of $0.019 \pm$ $0.013 \mathrm{gamma} / \mathrm{kg}$ per min and the measurements were repeated.

Since application of each of the different apex cardiographic systems took on the average 4 to 5 minutes, one observation period for all 6 transducers lasted 20 to 30 minutes. Because of technical problems with the tape-recording, 2 of the 168 registrations could not be analysed, so that paired comparison between each of the 6 transducers could be made in 26 of the 28 observation periods.

\section{MEASUREMENTS}

The electrocardiogram (lead II), internal phonocardiogram, aortic and left ventricular pressure, 
using Telco micromanometers, and the apex cardiogram were recorded simultaneously on frequency modulated magnetic tape and paper. Digital computer techniques were used to derive various measurements and to calculate median values on the beats present in 15 seconds of recording, as described previously (Willems, 1973, 1974). Conversion of the analogue data to digital form was carried out at a sampling rate of 250 samples/s. All analyses were done on an HP 2100 computer system.

The comparison of the 6 apex cardiographic transducer systems was made especially with respect to different measures of the rate of rise of the apex cardiogram and left ventricular pressure. The normalised derivative, that is the velocity of rise of the curve divided by its amplitude, was calculated using total as well as developed pressure $(\mathrm{dP} / \mathrm{dt} / \mathrm{P})$ or displacement $(\mathrm{dD} / \mathrm{dt} / \mathrm{D})$.

The first derivative was digitally derived from the apex cardiogram and pressure curves using a first difference method:

$$
(d P / d t)_{n}=\left(P_{n+1}-P_{n-1}\right) /\left(t_{n+1}-t_{n-1}\right),
$$

whereby $P_{n-1}, P_{n}$, and $P_{n+1}$ are any 3 consecutive pressures, or displacement measurements in case of displacement apex cardiograms measured $4 \mathrm{~ms}$ apart at times $t_{n-1}, t$, and $t_{n+1}$.

The derivation of $(\mathrm{dP} / \mathrm{dt}) /(\mathrm{kP}+\mathrm{c}),(\mathrm{dP} / \mathrm{dt}) / \mathrm{kP}$ and $(\mathrm{dP} / \mathrm{dt} / \mathrm{P})$, with $\mathrm{k}=32$, as approximations of contractile element shortening velocity during isovolumic systole has been discussed by several authors (Mason et al., 1970; Falsetti et al., 1971). In analogue to the derivation from left ventricular pressure data we have calculated similar indices from the apex cardiogram.

Since no real zero reference level exists in apex cardiography, the level of the 0 point was used as a substitute for the determination of total pressure or displacement, whereas the $C$ point was used as reference for developed apical displacement or pressure.

Force velocity curves were obtained by plotting $(\mathrm{dP} / \mathrm{dt}) / \mathbf{P}_{\mathrm{dev}}$ and $(\mathrm{dP} / \mathrm{dt}) / \mathrm{P}_{\text {total }}$ data on the ordinate versus, respectively, developed and total pressure or displacement, on the abscissa, for every separate beat and for a composite of all beats present in the recording. Straight line fitting was done through the points of the descending portion of the force velocity curve in case of total pressure or displacement. $\mathrm{V}_{\max }$ was obtained by extrapolation to zero in case of developed pressure or displacement by means of a polynomial curve fitting routine of degree one and degree two. $V_{\max }$ and $V_{C E}$ data are expressed in units per second denoted as $\mathbf{s}^{-1}$.

When normalised derivatives are digitally computed the sensitivity at which apex cardiograph curves are recorded does not influence the result, thereby allowing calculation of these indices from calibrated as well as from non-calibrated recordings.

Total diastolic deflection of the apex cardiogram was determined in the conventional manner (Benchimol and Dimond, 1963; Tavel, 1967) by measuring the vertical distance between the beginning of the upstroke ( $\mathrm{C}$ point) and nadir of the curve ( 0 point) as a percentage of the total height of the curve. The time intervals from the $\mathrm{C}$ to 0 point and from $C$ to the peak of derivative of the apex cardiogram and left ventricular pressure curve have also been calculated.

Whenever indices were computed from single beats a representative value for the recording period was computed by deleting the two values most extremely located from the median and averaging the results of the remaining beats. Since differences between $V_{\max }$ values obtained in this manner from individual beats and from a composite of beats were insignificant, only $V_{\max }$ values obtained with the latter method are reported in this study.

\section{STATISTICAL ANALYSES}

For each haemodynamic intervention, averages and standard deviations were calculated for each of the various measurements on corresponding apex cardiographic and left ventricular pressure data.

Pooled data from all recording sessions were used to compute mean differences and paired $t$ tests in the comparison of the 6 different apex cardiograph transducer systems.

Variability of the results was tested by calculating the deviations from the average in each observation period and expressing the results as percentages. The average of the 6 results obtained in each observation period for each measurement from the apex cardiogram and corresponding left ventricular pressure was taken as 100 per cent. In this way variability of measurements of different nature, for example left ventricular systolic pressure and peak $(\mathrm{dP} / \mathrm{dt} / \mathrm{P})$, or magnitude could be compared.

\section{Results}

\section{AMPLITUDE MEASUREMENTS AND TIME} INTERVALS

Apex cardiograms taken with the 6 transducer systems during control conditions and during isoprenaline and angiotensin administration are illustrated in Fig. 1-3. The tracings were comparable with respect to their morphological appearances. Variable recordings, however, could be obtained with only minimal changes in location of the pick-up, as shown in Fig. 4. 

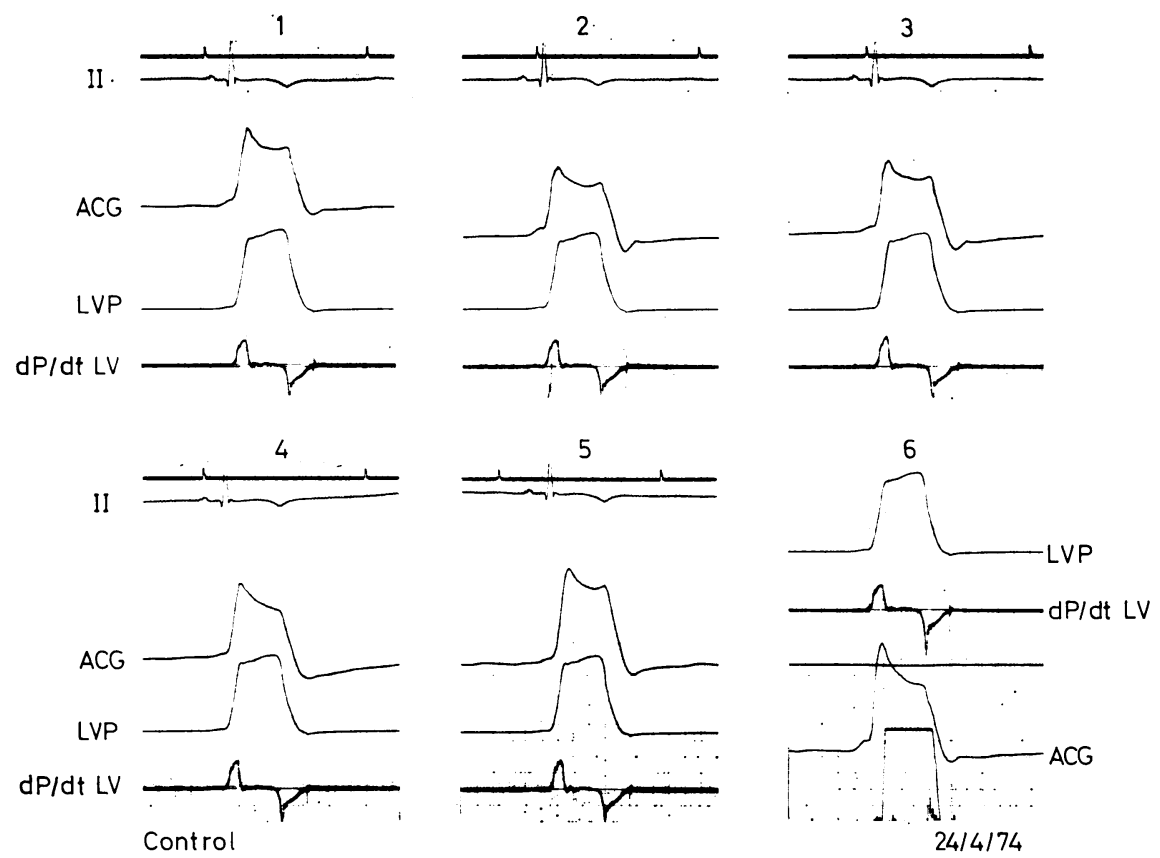

Fig. 1 Representative tracings obtained with the 6 different transducer systems during control conditions. For pick-up identification see Methods. Abbreviations: ACG, apex cardiogram; LVP, left ventricular pressure; dp/dt LV, first derivative of left ventricular pressure.

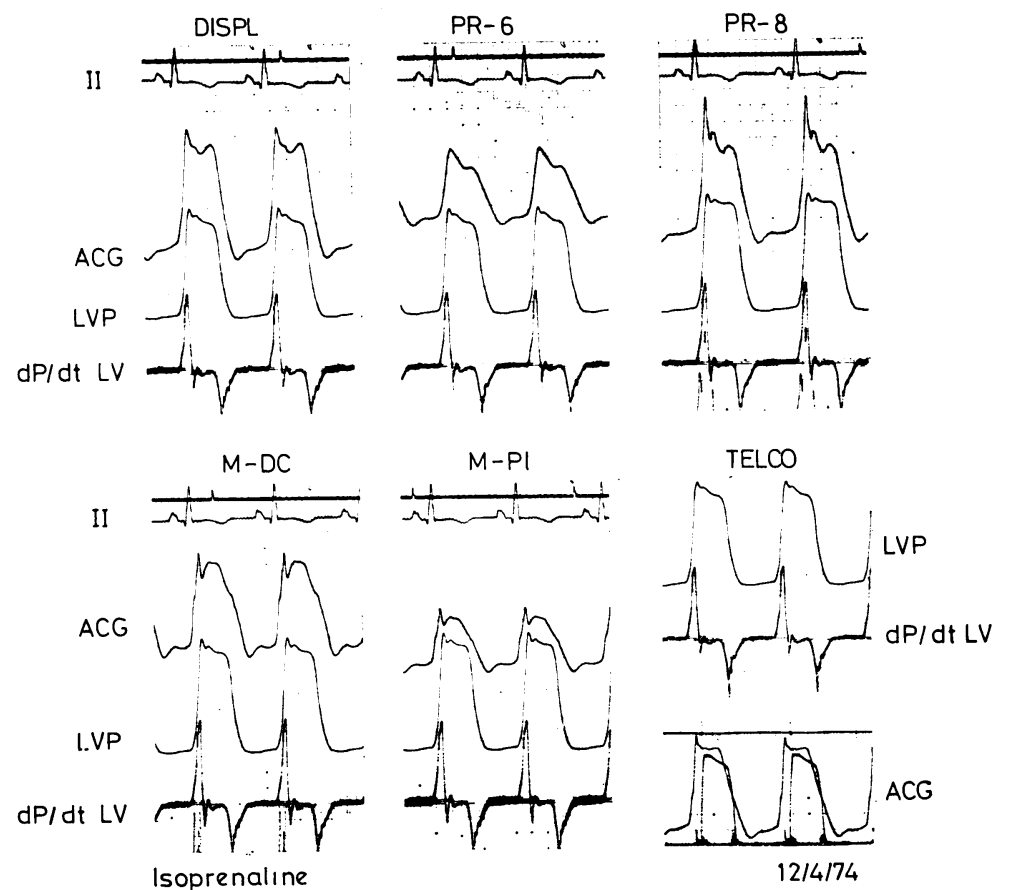

Fig. 2 Representative tracings obtained with the 6 different transducer systems during isoprenaline infusion. Abbreviations: see legend Fig. 1; DISPL, displacement transducer no. 4; M-DC, Marey DC, M-PI, Marey piezoelectric; $P R-6$ and $P R-8$, fluid-filled pressure transducer with membrane of, respectively, 6 and $8 \mathrm{~mm}$. 

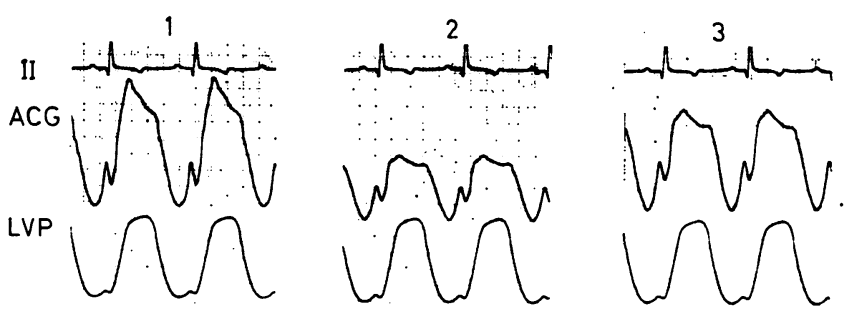

$d P / d t$ LV
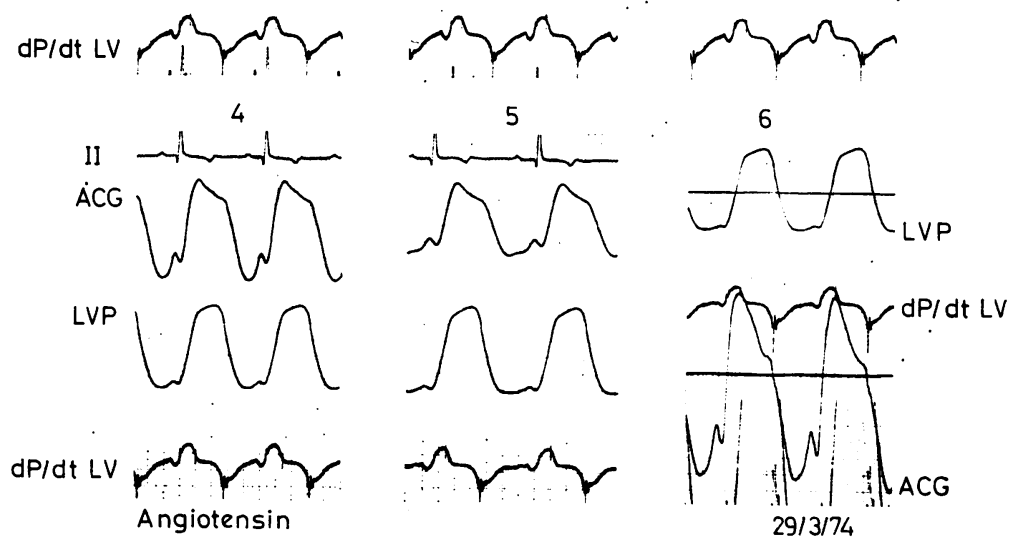

$29 / 3 / 74$

Fig. 3 Representative tracings obtained with the 6 different transducer systems during angiotensin administration. Abbreviations: see Fig. 1.

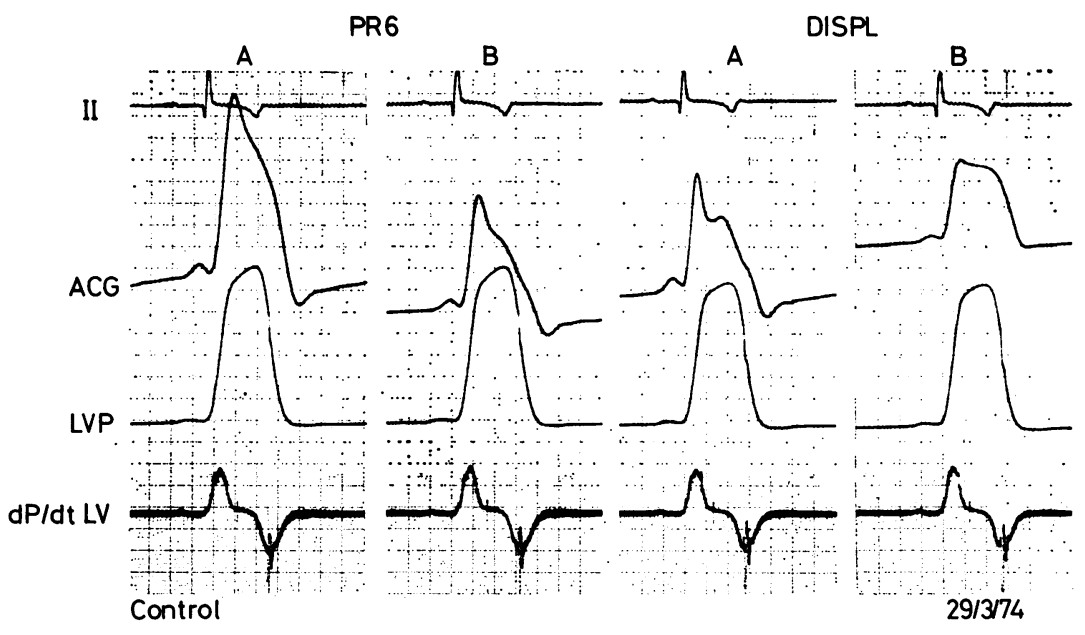

Fig. 4 Illustration of variability in apex cardiograph morphology, especially of the systolic plateau, as a result of only minor displacement of the pick-up location. Abbreviations: see Fig. 2.

Mean values of total diastolic deflection, expressed as a percentage of the total apex cardiograph height, are given in Table 1 , for each of the pick-up systems. The values obtained with the displacement measuring systems (transducers 2,3 , and 4$)$ were significantly higher $(P<0.01)$ than those obtained with the pressure measuring devices (transducers 1, 5, and 6).

Small insignificant differences could be demonstrated in the $\mathrm{C}$ to 0 time intervals. The apex cardiograms recorded with the pressure measuring transducer, equipped with a sensing diameter of 
Table 1 Comparison between total diastolic deflections and time intervals derived from 6 apex cardiographic transducer systems and corresponding left ventricular systolic and end-diastolic pressure and peak time

\begin{tabular}{|c|c|c|c|c|c|c|c|c|c|}
\hline & \multicolumn{6}{|c|}{ Apex cardiographic transducer system } & \multirow{2}{*}{\multicolumn{3}{|c|}{$\begin{array}{l}\text { Statistically significant differences between } \\
\text { results }\end{array}$}} \\
\hline & \multirow[t]{2}{*}{1} & \multirow[t]{2}{*}{2} & \multirow[t]{2}{*}{3} & \multirow[t]{2}{*}{4} & \multirow[t]{2}{*}{5} & \multirow[t]{2}{*}{6} & & & \\
\hline & & & & & & & $P<0.001$ & $P<0.01$ & $P<0.05$ \\
\hline \multicolumn{10}{|l|}{ Apex cardiogram } \\
\hline $\begin{array}{l}\text { Total diastolic } \\
\text { deflection } \%\end{array}$ & $\begin{array}{l}19 \cdot 8 \\
(1 \cdot 4)\end{array}$ & $\begin{array}{l}26 \cdot 4 \\
(1 \cdot 8)\end{array}$ & $\begin{array}{l}26 \cdot 2 \\
(1 \cdot 8)\end{array}$ & $\begin{array}{l}23 \cdot 2 \\
(1 \cdot 8)\end{array}$ & $\begin{array}{l}19 \cdot 2 \\
(1 \cdot 1)\end{array}$ & $\begin{array}{c}21 \cdot 4 \\
(1 \cdot 4)\end{array}$ & $\begin{array}{l}1-3 ; 2-5 \\
3-5 ; 3-6\end{array}$ & $2-6$ & $1-4 ; 4-5$ \\
\hline $\begin{array}{l}\text { C-to peak } \\
\text { derivative (ms) }\end{array}$ & $\begin{array}{l}29 \cdot 7 \\
(1 \cdot 8)\end{array}$ & $\begin{array}{l}30 \cdot 7 \\
(2 \cdot 0)\end{array}$ & $\begin{array}{l}31 \cdot 1 \\
(1 \cdot 6)\end{array}$ & $\begin{array}{l}31 \cdot 3 \\
(1 \cdot 7)\end{array}$ & $\begin{array}{l}36.6 \\
(1.5)\end{array}$ & $\begin{array}{l}31.8 \\
(1.9)\end{array}$ & $1-5$ & $3-5$ & $\begin{array}{l}2-5 ; 4-5 \\
5-6\end{array}$ \\
\hline $\begin{array}{l}\text { C-0 interval } \\
\text { (ms) }\end{array}$ & $\begin{array}{l}399 \\
(15)\end{array}$ & $\begin{array}{l}391 \\
(14)\end{array}$ & $\begin{array}{l}396 \\
(17)\end{array}$ & $\begin{array}{l}394 \\
(12)\end{array}$ & $\begin{array}{l}395 \\
(11)\end{array}$ & $\begin{array}{l}401 \\
(15)\end{array}$ & & & $1-2$ \\
\hline $\begin{array}{l}\text { Heart rate } \\
\text { (beats } / \mathrm{min} \text { ) } \\
L V \text { pressure }\end{array}$ & $\begin{array}{l}76 \cdot 2 \\
(4 \cdot 1)\end{array}$ & $\begin{array}{l}77 \cdot 0 \\
(4 \cdot 6)\end{array}$ & $\begin{array}{l}77 \cdot 1 \\
(4 \cdot 7)\end{array}$ & $\begin{array}{l}76 \cdot 8 \\
(4 \cdot 5)\end{array}$ & $\begin{array}{l}76 \cdot 7 \\
(4 \cdot 1)\end{array}$ & $\begin{array}{l}78 \cdot 4 \\
(4 \cdot 5)\end{array}$ & & & \\
\hline $\begin{array}{l}\text { Syst. press. } \\
\text { (mmHg) }\end{array}$ & $\begin{array}{r}135.9 \\
(6.9)\end{array}$ & $\begin{array}{r}135 \cdot 3 \\
(6 \cdot 9)\end{array}$ & $\begin{array}{r}135 \cdot 5 \\
(7 \cdot 1)\end{array}$ & $\begin{array}{r}135 \cdot 2 \\
(7 \cdot 1)\end{array}$ & $\begin{array}{r}133.5 \\
(6.8)\end{array}$ & $\begin{array}{r}137 \cdot 0 \\
(7 \cdot 1)\end{array}$ & & & \\
\hline LVEDP (mmHg) & $\begin{array}{c}11 \cdot 8 \\
(1 \cdot 2)\end{array}$ & $\begin{array}{l}12.0 \\
(1.4)\end{array}$ & $\begin{array}{l}11 \cdot 0 \\
(1 \cdot 3)\end{array}$ & $\begin{array}{c}11 \cdot 4 \\
(1.5)\end{array}$ & $\begin{array}{l}11.0 \\
(1.3)\end{array}$ & $\begin{array}{l}11 \cdot 1 \\
(1 \cdot 4)\end{array}$ & & & \\
\hline $\begin{array}{l}\mathrm{C} \text {-to peak } \\
\text { derivative (ms) }\end{array}$ & $\begin{array}{l}53 \cdot 4 \\
(1 \cdot 6)\end{array}$ & $\begin{array}{l}52 \cdot 1 \\
(1 \cdot 5)\end{array}$ & $\begin{array}{l}53 \cdot 6 \\
(1 \cdot 7)\end{array}$ & $\begin{array}{l}53.5 \\
(1.6)\end{array}$ & $\begin{array}{l}54 \cdot 6 \\
(1 \cdot 8)\end{array}$ & $\begin{array}{l}54 \cdot 4 \\
(2 \cdot 0)\end{array}$ & & & \\
\hline
\end{tabular}

Methods: (1) pressure (8 mm); (2) Marey DC; (3) Marey piezo; (4) displacement; (5) pressure (6 mm); (6) Telco pick-up.

Total number of paired observations, 26; LVDEP, left ventricular end-diastolic pressure.

Mean and standard errors of the mean (between parentheses) are given.

Table 2 'Contractility' indices derived from left pressure data and the apex cardiogram, recorded by 6 different transducers: means and standard errors are given ( $N=26$ paired observations)

\begin{tabular}{|c|c|c|c|c|c|c|}
\hline & \multicolumn{6}{|c|}{ Transducer } \\
\hline & 1 & 2 & 3 & 4 & 5 & 6 \\
\hline \multicolumn{7}{|l|}{ LV pressure } \\
\hline $\mathrm{dP} / \mathrm{dt} \max$ & $\begin{array}{l}2257 \\
(151)\end{array}$ & $\begin{array}{l}2296 \\
(160)\end{array}$ & $\begin{array}{l}2347 \\
(171)\end{array}$ & $\begin{array}{l}2281 \\
(160)\end{array}$ & $\begin{array}{l}2273 \\
(157)\end{array}$ & $\begin{array}{l}2310 \\
(174)\end{array}$ \\
\hline peak $\left(\mathrm{dP} / \mathrm{dt} / \mathbf{P}_{\mathbf{T}}\right)$ & $\begin{array}{l}60.5 \\
(1.5)\end{array}$ & $\begin{array}{l}59.7 \\
(1.5)\end{array}$ & $\begin{array}{c}61.8 \\
(2.0)\end{array}$ & $\begin{array}{c}59 \cdot 8 \\
(1.8)\end{array}$ & $\begin{array}{c}61.3 \\
(1.6)\end{array}$ & $\begin{array}{c}60 \cdot 3 \\
(1.4)\end{array}$ \\
\hline $\mathbf{V}_{\max }$ tot $\mathbf{P}$ & $\begin{array}{c}1.97 \\
(0.05)\end{array}$ & $\begin{array}{c}1.97 \\
(0.05)\end{array}$ & $\begin{array}{c}2.00 \\
(0.05)\end{array}$ & $\begin{array}{c}1.98 \\
(0.05)\end{array}$ & $\begin{array}{c}1.96 \\
(0.05)\end{array}$ & $\begin{array}{r}1.98 \\
(0.06)\end{array}$ \\
\hline \multicolumn{7}{|l|}{$V_{\max } \operatorname{dev} P$} \\
\hline$-\operatorname{lin}$ & $\begin{array}{c}3.50 \\
(0.08)\end{array}$ & $\begin{array}{c}3.51 \\
(0.07)\end{array}$ & $\begin{array}{c}3.51 \\
(0.10)\end{array}$ & $\begin{array}{c}3.46 \\
(0.08)\end{array}$ & $\begin{array}{c}3.48 \\
(0.08)\end{array}$ & $\begin{array}{c}3.40 \\
(0.08)\end{array}$ \\
\hline- poly & $\begin{array}{c}4.54 \\
(0.11)\end{array}$ & $\begin{array}{c}4.53 \\
(0.10)\end{array}$ & $\begin{array}{c}4.50 \\
(0.14)\end{array}$ & $\begin{array}{c}4.42 \\
(0.11)\end{array}$ & $\begin{array}{c}4.44 \\
(0.09)\end{array}$ & $\begin{array}{c}4.31 \\
(0 \cdot 10)\end{array}$ \\
\hline \multicolumn{7}{|l|}{ Apex cardiogram } \\
\hline peak $\left(\mathrm{dP} / \mathrm{dt} / \mathbf{P}_{\mathrm{T}}\right)$ & $\begin{array}{l}43 \cdot 1 \\
(2 \cdot 2)\end{array}$ & $\begin{array}{l}38 \cdot 9 \\
(2 \cdot 2)\end{array}$ & $\begin{array}{l}39 \cdot 0 \\
(2 \cdot 2)\end{array}$ & $\begin{array}{l}39 \cdot 9 \\
(2 \cdot 1)\end{array}$ & $\begin{array}{l}37.8 \\
(1.6)\end{array}$ & $\begin{array}{l}40 \cdot 4 \\
(2 \cdot 0)\end{array}$ \\
\hline$V_{\max }$ tot $P$ & $\begin{array}{c}2.50 \\
(0 \cdot 14)\end{array}$ & $\begin{array}{c}2 \cdot 37 \\
(0 \cdot 10)\end{array}$ & $\begin{array}{c}2 \cdot 27 \\
(0 \cdot 10)\end{array}$ & $\begin{array}{c}2 \cdot 16 \\
(0 \cdot 10)\end{array}$ & $\begin{array}{c}1.81 \\
(0.09)\end{array}$ & $\begin{array}{c}2 \cdot 16 \\
(0 \cdot 10)\end{array}$ \\
\hline $\mathrm{V}_{\max } \operatorname{dev} \operatorname{lin}$ & $\begin{array}{c}4 \cdot 65 \\
(0 \cdot 16)\end{array}$ & $\begin{array}{c}4.85 \\
(0 \cdot 14)\end{array}$ & $\begin{array}{c}4 \cdot 67 \\
(0 \cdot 17)\end{array}$ & $\begin{array}{c}4 \cdot 35 \\
(0 \cdot 14)\end{array}$ & $\begin{array}{c}3.58 \\
(0.14)\end{array}$ & $\begin{array}{c}4.22 \\
(0.15)\end{array}$ \\
\hline$V_{\max }$ dev poly & $\begin{array}{c}5.94 \\
(0 \cdot 19)\end{array}$ & $\begin{array}{c}6 \cdot 34 \\
(0 \cdot 25)\end{array}$ & $\begin{array}{c}6.00 \\
(0.25)\end{array}$ & $\begin{array}{c}5 \cdot 59 \\
(0 \cdot 19)\end{array}$ & $\begin{array}{c}4 \cdot 50 \\
(0 \cdot 20)\end{array}$ & $\begin{array}{c}5 \cdot 45 \\
(0 \cdot 23)\end{array}$ \\
\hline
\end{tabular}

Transducer systems: (1) pressure (8 mm); (2) Marey DC; (3) Marey piezo; (4) displacement; (5) pressure (6 mm); (6) Telco pick-up. $\mathbf{P}$, pressure; tot, total; dev, developed; lin and poly, respectively linear and polynomial fitting (see Methods); $\mathbf{P}_{\mathrm{T}}$, total pressure.

$6 \mathrm{~mm}$, had a significantly longer $\mathrm{C}$ to peak time, as shown in Table 1 .

\section{INDICES DERIVED FROM NORMALISED DERIVATIVE}

Measures derived from left ventricular pressure data were very reproducible (Table 2 ). The maximal difference in any of the 6 recordings obtained during application of the 6 different apex cardiographic transducer systems was 3.4 per cent, namely for left ventricular end-diastolic pressure. Variability in 'contractility' measurements derived from left ventricular pressure averaged between 0.5 and 1.9 per cent (Table 3 ).

Indices derived from the apex cardiogram using 6 different transducer systems showed a significantly greater variability (Table 2 ). The average variation from the mean for different measurements varied between 3.2 and 8.1 per cent (Table 3). One system showed average deviations from the mean up to 20 per cent. The results obtained with this pick-up (no. 5) were significantly different from the others. 
Table 3 Average results and deviations from mean, in absolute values $(\Delta)$ and as relative differences $(\%)$ for each of 6 different apex cardiographic transducer systems, using pooled data $(N=26$ observation periods)

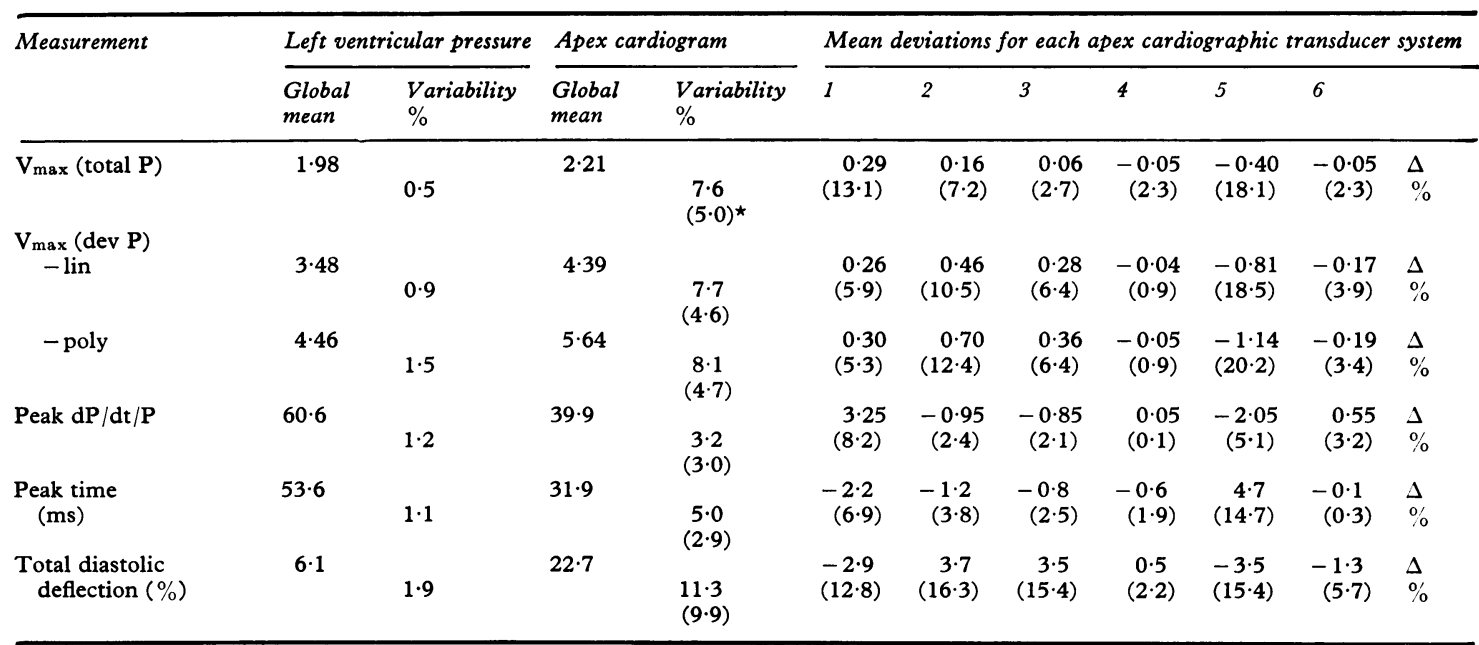

Methods: (1) pressure (8 mm); (2) Marey DC; (3) Marey piezo; (4) displacement; (5) pressure (6 mm); (6) Telco.

*Average variability data, expressed as per cent, after deleting results of pick-up 5 .

Table 4 Mean absolute differences $(\bar{D})$ in peak $d P / d t / P$ values obtained by 6 different apex cardiograph transducer systems and corresponding paired $t$ tests

\begin{tabular}{llrrrr}
\hline Method & 2 & \multicolumn{1}{l}{3} & \multicolumn{2}{l}{5} & \multicolumn{1}{l}{5} \\
\hline 1 & $4.21(1)$ & 4.06 & 3.25 & 5.33 & 2.69 \\
& $1.68(2)$ & 1.49 & 1.69 & $2.64^{\star}$ & 1.58 \\
2 & & -0.15 & -0.96 & 1.12 & -1.52 \\
& & -0.09 & -0.39 & 0.46 & -0.79 \\
3 & & -0.81 & 1.27 & -1.37 \\
4 & & -0.35 & 0.44 & -0.64 \\
& & & 2.08 & -0.56 \\
5 & & & 1.15 & -0.30 \\
& & & & -2.63 \\
& & & & & -1.22 \\
\hline
\end{tabular}

Methods: (1) pressure (8 mm); (2) Marey DC; (3) Marey piezo; (4) displacement; (5) pressure $(6 \mathrm{~mm})$; (6) Telco.

$\star$ Significance level : $\mathbf{P}<0.05$.

Standard deviations $\left(S_{D}\right)$, not presented in this and following table, can be derived using the formula

$$
\mathrm{S}_{\overline{\mathrm{D}}}^{-}=\frac{\overline{\mathrm{D}}}{\mathrm{t}}
$$

Total number of paired observations.

A significant part of the observed variability was due to this pick-up (Table 2). By deleting transducer no. 5 , variability for different measurements decreased significantly to an average of 2.9 to 5.6 per cent (Table 3).

The most consistent results were obtained for peak ( dP/dt/P). Two matrices with mean differences and corresponding paired $t$ tests of measurements derived from the apex cardiogram, recorded with the 6 different recording systems, are given in Tables 4 and 5. Most differences in these and other
Table 5 Mean absolute differences between so-called $V_{\text {max }}$ indices $\dagger$ using total pressure or displacement obtained by 6 different apex cardiograph pick-up systems

\begin{tabular}{|c|c|c|c|c|c|}
\hline Method & 2 & 3 & 4 & 5 & 6 \\
\hline \multirow[t]{2}{*}{1} & $0 \cdot 13(1)$ & 0.23 & $0 \cdot 34$ & 0.69 & 0.34 \\
\hline & $1 \cdot 14(2)$ & 1.55 & $2 \cdot 77^{\star}$ & $5 \cdot 12^{\star \star \star}$ & $2 \cdot 63$ \\
\hline \multirow[t]{2}{*}{2} & & $0 \cdot 11$ & $0 \cdot 21$ & 0.57 & 0.21 \\
\hline & & 1.37 & $2 \cdot 64^{\star}$ & $5 \cdot 53 \star \star \star$ & $2 \cdot 05$ \\
\hline \multirow{2}{*}{3} & & & $0 \cdot 10$ & 0.46 & $0 \cdot 10$ \\
\hline & & & $1 \cdot 13$ & $3.99 \star \star \star$ & $1 \cdot 28$ \\
\hline 4 & & & & $\begin{array}{l}0 \cdot 36 \\
3 \cdot 42^{\star \star}\end{array}$ & $\begin{array}{l}0.003 \\
0.03\end{array}$ \\
\hline 5 & $\begin{array}{l}\text { (1) mean } \\
\text { (2) paired }\end{array}$ & $\begin{array}{l}\text { lifferen } \\
t \text { tests }\end{array}$ & $\bar{D})$ & & $\begin{array}{l}-0.35 \\
-3.33^{\star \star}\end{array}$ \\
\hline
\end{tabular}

Methods: (1) pressure (8 mm); (2) Marey DC; (3) Marey piezo; (4) displacement; (5) pressure (6 mm); (6) Telco.

$\star P<0.05 ; \star \star P<<0.01 ; \star \star \star P<<0.001$.

†Using (dP/dt) $/ k P$ tot with $K=32$.

Total number of paired observations: 26 .

comparisons were not significant except for pick-up 5.

CORRELATION BETWEEN LEFT

VENTRICULAR PRESSURE AND APEX

CARDIOGRAPHIC INDICES

Correlations were calculated between various indices derived from the normalised apex cardiographic derivative and corresponding left ventricular pressure measures for each of the 6 different apex cardiographic transducer systems. Correlation coefficients varied between 0.35 and 0.72 . None of the 6 transducer systems showed a superiority in this respect. The highest correlations in the present 
investigation were found between left ventricular pressure and apex cardiographic 'contractility' indices, using developed pressure or displacement.

\section{Discussion}

Whereas previous authors (Ginn et al., 1967; Gleichmann, 1968; Motomura et al., 1973; Willems, 1973; Denef et al., 1975; Dübel et al., 1975) have tested the reproducibility of the apex cardiogram using the same transducer applied on the same subjects at different time intervals, in the present study we analysed the comparability and reproducibility of the apex cardiogram recorded with 6 different transducer systems.

\section{REPRODUCIBILITY USING SAME}

\section{TRANSDUCER}

Ginn et al. (1967) have studied day-to-day reproducibility of the A wave in the resting and postexercise apex cardiogram. Apex cardiograms were recorded on 3 different days in 24 normal subjects and in 22 patients with ischaemic heart disease. Though the coefficient of variation, defined as the standard error deviation within subjects divided by the mean of the group, was relatively high (between 28 and $33 \%$ ), the authors concluded that reproducibility was not an important limiting factor to the discriminatory ability of the method.

A systematic study on reproducibility of 21 different measurements, including some indices derived from the first derivative of the apex cardiogram, has been published by Dübel et al. (1975). Recordings were made in 15 subjects at 4 different time intervals, two the first day, 10 minutes apart, the third and fourth, respectively, 2 and 10 days later. Analysis of variance was done and all F-tests were below $2 \cdot 7$, which was the 5 per cent significance level.

Inter- and intraobserver variation on the calibrated derivative from the apex cardiogram has been studied by Denef et al. (1975). The intraobserver variation was determined in 23 subjects by recording the apex cardiogram twice with the same transducer, within an interval of at least one week. The variation was 11 to 25 per cent for data derived from the normalised apex cardiogram derivative. Variability results between 28 and 44 per cent were obtained for non-normalised amplitudes.

An average relative difference of 8 per cent in peak normalised derivative values was found by Motomura et al. (1973) in 16 patients, with apex cardiograms recorded at one- or two-week intervals, using the same equipment.

COMFARABILITY OF APEX CARDIOGRAM RECORDED WITH DIFFERENT TRANSDUCERS Within the same laboratory results may be repro- ducible, but this may nct be so between different laboratories. Indeed, comparison of morphological features of apex cardiograms, recorded in different laboratories, has been difficult in the past (Craige, 1973). This resulted mainly from the use of varying techniques and of transducer systems unsuitable for recording low frequency vibrations (Reale, 1967; Johnson et al., 1971; Willems, 1973). It is now widely accepted that transducers should be used with an adequately long time constant, of at least $2.5 \mathrm{~s}$, the ideal being an infinite time constant (Wesseling and Van Vollenhoven, 1969; Johnson et al., 1971; Willems, 1973; Reddy et al., 1976).

In the present study a comparison was made of results obtained with 6 different apex cardiographic transducer systems, obeying this requirement. Reproducibility was tested under well-controlled laboratory conditions. Recordings were made before, during, and after controlled infusion of angiotensin and isoprenaline in 7 dogs. Our objective was to examine variability, as a result solely of differences in apex cardiograph transducer systems. In particular, indices derived from the normalised derivative have been analysed. Analysis of the recordings was done entirely by computer techniques, thereby eliminating observer measurement variability.

Measures derived from left ventricular pressure were very reproducible. Variability in results of 'left ventricular pressure contractility' measures averaged 0.5 and 1.9 per cent. This proves that during the recording sessions the haemodynamic status of the animals was stable and that the computer techniques used for calculating did not introduce any appreciable degree of variation.

Indices derived from the apex cardiogram, using 6 different transducer systems, showed significantly greater variations, with mean results varying between 3.2 and 8.1 per cent. One pick-up showed deviations up to 20 per cent from the pooled mean data. Deleting results of this device decreased significantly the variability, to an average of 2.9 to 5.0 per cent for indices derived from the normalised derivative.

Results on peak (dP/dt/P), respectively peak $(\mathrm{dA} / \mathrm{dt} / \mathrm{A})$, were most consistent. If we take the mean obtained with all 6 transducers as the 'real' peak $(\mathrm{dP} / \mathrm{dt} / \mathrm{P})$ value, then deviations from this average varied between 0.1 and 8.2 per cent (mean 3.2). Most of the differences between results obtained with the different transducers were not significant, except for one transducer system.

DETERMINING FACTORS OF VARIABILITY Derivation of measurements from the normalised derivative with regard to total pressure is dependent on the total height of the diastolic deflection. 


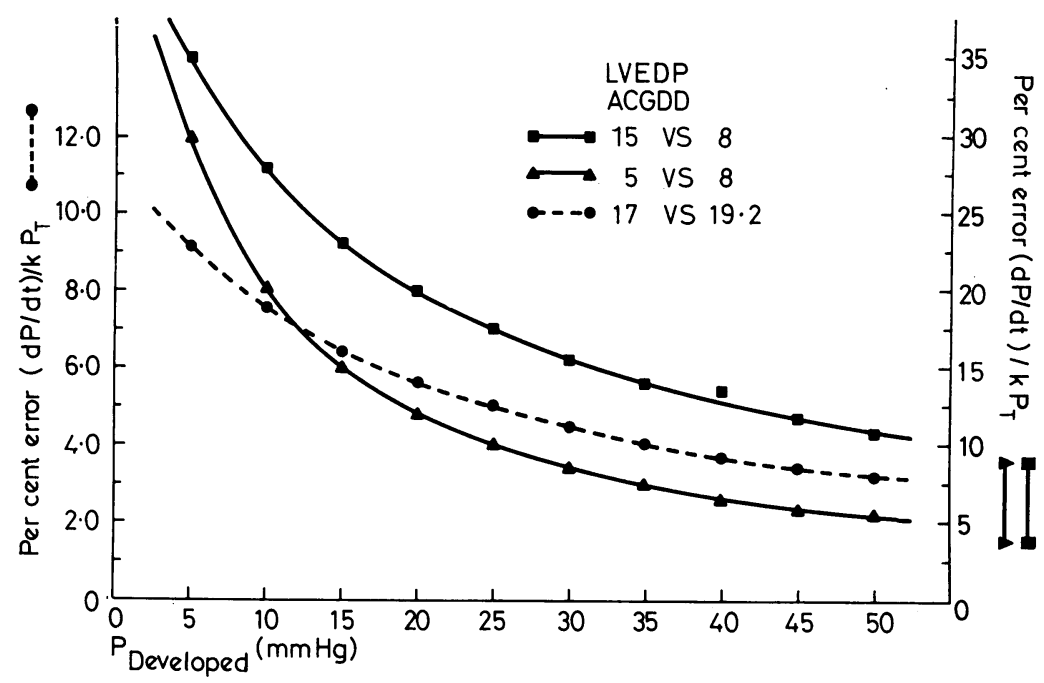

Fig. 5 Graphic representation of the error, in per cent, of $(d P / d t) / P$ ratios introduced by using incorrect left ventricular end-diastolic pressures (LVEDP) or wrong apex cardiographic diastolic deflections (ACGDD) of the apex cardiogram. The full line denoted by squares indicates the underestimation introduced when $15 \mathrm{mmHg}$ is used instead of $8 \mathrm{~mm}$ as LVEDP. The two other lines illustrate the overestimation when values of 5 and 17 are used instead of, respectively, 8 and 19.2. The highest errors in $(d P / d t) / P$ ratios are found at low developed pressures.

Errors in the determination of this measurement largely influence peak $(\mathrm{dP} / \mathrm{dt} / \mathrm{P})$ and so-called $\mathrm{V}_{\max }$ indices derived from total pressure, especially when end-diastolic deflections are low, as shown in Fig. 5. The derivation of measurements from the normalised apex cardiogram derivative, therefore, requires that the time-constant of the apparatus should be long, that is at least 2.5 to 5 seconds, otherwise variable differentiation will take place with changes in the $R R$ interval. With varying diastolic periods the total diastolic deflection might be artificially different, thereby influencing $(\mathrm{dP} / \mathrm{dt} / \mathrm{P})$ or $(\mathrm{dA} / \mathrm{dt} / \mathrm{A})$ ratios.

Total diastolic deflections of the apex cardiograms recorded in the present study with displacement measuring systems were significantly higher than in apex cardiograms recorded with pressure measuring systems, though the time constant of all systems exceeded 2.5 seconds. Correspondingly, peak values of normalised derivatives were slightly lower in apex cardiograms recorded with displacement measuring devices, with the exception of pick-up no. 5, which showed also other significant aberrations. The average interval from the onset of the rise (point $\mathrm{C}$ ) of the apex cardiogram to the peak of the derivative was significantly longer in apex cardiograms recorded with this device, because of inappropriate frequency characteristics.
Indeed, besides good frequency response at the low end of the spectrum the apex cardiographic system should also have good response characteristics in the high frequency range. Similarly, derivation of indices of contractility from left ventricular pressure data requires high-fidelity micromanometer recordings (Mason et al., 1970; Mirsky et al., 1972). Differences found in the present study between results of the 6 apex cardiographic transducer systems may be partially attributed to differences in application technique, but are probably a result of differences in response characteristics in the high frequency range.

Differences in technique of application of the 6 transducer systems were kept as minimal as possible. Such differences, however, are unavoidable, for example with respect to the exact place at the site of maximal impulse and the use of the same application pressure, as a result of the different pick-up diameters and sensing mechanisms.

Response characteristics of the 6 apex cardiographic transducers in the high frequency range were variable. In order to ensure maximal reproducibility of the normalised apex cardiographic derivative, linearity is needed, at least to $50 \mathrm{~Hz}$, with some filtering to produce well-recognised alterations in roll-off features. Indeed, as a result of the thoracic wall resonance, high frequency heart sounds 
affect the apex cardiogram more than the left ventricular pressure curve. In addition, in unfiltered high-fidelity left ventricular pressure curves, notches corresponding to high frequency components of the first sound may cause spuriously large $(\mathrm{dP} / \mathrm{dt}) / \mathrm{P}$ ratios.

\section{CONCLUSION AND CLINICAL APPLICATIONS} In order to assure maximal reproducibility, technical characteristics of the recording device should be taken into account and an optimal recording technique be used. This has been underlined by several investigators with respect to the morphological features of the apex cardiogram (Kesteloot et al., 1969; Willems, 1973). From the present study it is evident that the same holds true for measurements derived from its normalised derivative.

This conclusion should not be interpreted as a criticism of apex cardiography but should caution against an uncritical comparison of results obtained by authors using different devices.

Two important statements can be made as a result of our study. Firstly, the average differences between different transducers did not exceed 5 to 8 per cent. The mean difference in the peak amplitude of the normalised derivative obtained with the 6 different transducers was only 3.2 per cent. This was the best measurement with regards to reproducibility in the present investigation. These findings in the dog obtained under ideal circumstances, however, cannot be transferred to routine patient care. To these results one should compare the 8 and 11 per cent variation figures obtained by Motomura et al. (1973) and Denef et al. (1975) in human subjects. It has been shown that these figures are no limiting factor in discriminating patient groups with normal and abnormal myocardial function. Secondly, results of so many other techniques and measurements (as for example LVEDP, cardiac index, ejection fraction) vary even more significantly as emphasised by Spodick (1975). Variations in observer performance, including perception and interpretation, for other data, on which even critical decisions are made, can be so great that they should encourage us to use non-invasive objective measurements, such as derived from the apex cardiogram, echocardiography, or quantitative scintigraphy, and to refine these as much as possible.

\section{References}

Benchimol, A., and Dimond, E. G. (1963). The normal and abnormal apexcardiogram. Its physiologic variation and its relation to intracardiac events. American fournal of Cardiology, 12, 368-382.

Craige, E. (1973). The apexcardiogram. In Non-invasive Cardiology, pp. 1-38, ed A. M. Weissler. Grune and
Stratton, New York.

Denef, B., De Geest, H., and Kesteloot, H. (1973). Influence of changes in myocardial contractility on the height and slope of the calibrated apexcardiogram. American fournal of Cardiology, 32, 662-669.

Denef, B., Popeye, R., De Geest, H., and Kesteloot, H. (1975). On the clinical value of calibrated displacement apexcardiography. Circulation, 51, 541-551.

Dübel, H. P., Günther, K. H., and Witte, J. (1975). Kalibrierte und differenzierte Apexkardiographie. 2. Mitteilung: Untersuchungen zur Reproduzierbarkeit. Deutsche Gesundheitswesen, 30, 654-656.

Falsetti, H. L., Mates, R. E., Greene, D. C., and Bunnel, I. L. (1971). $V_{\max }$ as an index of contractile state in man. Circulation, 43, 467-479.

Fincker, J. L., Arnold, P., Brandt, C., Vergnes, R., and Meyer, P. (1971). La dérivée première du cardiogramme apexien. Technique et résultats chez les sujets normaux. Archives des Maladies du Coeur et des Vaisseaux, 64, 11941210.

Ginn, W. M., Sherwin, R. W., Harrison, W. K., and Baker, B. M., jun (1967). Apexcardiography: use in coronary heart disease and reproducibility. American Heart Fournal, 73, 168-180.

Gleichmann, U. (1968). Neues Verfahren zur Registrierung des Apexkardiogrammes ( $A C G)$, p. 19. Habilitationsschrift, University of Düsseldorf.

Hartman, H., and Snellen, H. A. (1960). The apexcardiogram. In Proceedings Third European Congress Cardiology, Rome, Part B, pp. 111-113. Rome.

Johnson, J. M., Siegel, W., and Blomqvist, G. (1971). Characteristics of transducers used for recording the apexcardiogram. Fournal of Applied Physiology, 31, 796-800.

Kesteloot, H., Willems, J., and Van Vollenhoven, E. (1969). On the physical principles and methodology of mechanocardiography. Acta Cardiologica, 24, 147-160.

Mason, D. T., Spann, J. F., jun, and Zelis, R. (1970). Quantification of contractile state of the intact human heart. Maximal velocity of contractile element shortening determined by the instantaneous relation between the rate of pressure rise and pressure in the left ventricle during isovolumic systole. American fournal of Cardiology, 26, 248-257.

Mirsky, I., Pasternac, A., and Ellison, R. C. (1972). General index for the assessment of cardiac function. American fournal of Cardiology, 30, 483-491.

Motomura, M., Omae, M., Uehata, H., Kumata, T., Yaginuma, T., Wakabayashi, A., and Konishi, T. (1973). An apex cardiographic index (peak $\mathrm{dA} / \mathrm{dt}$ )/A for the assessment of left ventricular function. Fapanese Heart fournal, 37, 1355-1359.

Nillsson, K., and Thulesius, O. (1973). A combined microphone for simultaneous recording of pulse and heart sounds. Biomedical Engineering, 8, 424-427; 431.

Reale, A. (1967). Evaluation of the contractile state of the human heart from the first derivative of the apexcardiogram. Circulation, 36, 933-941.

Reddy, P. S., Meno, F., Griff, F. W., O'Toole, J. D., and Shaver, J. A. (1976). Calibrated apexcardiography (abstract). Circulation, 53 and 54, Suppl. II, 98.

Spodick, D. H. (1975). On experts and expertise: the effect of variability in observer performance. American fournal of Cardiology, 36, 592-596.

Tavel, M. E. (1967). Clinical Phonocardiography and External Pulse Recording, pp. 156-172. Year Book Medical Publishers, Chicago.

Tricot, R., Cavailles, J., and Veber, G. (1966). Utilisation d'un capteur à variation d'inductance pour l'enrégistrement des phénomènes mécaniques cardiaques. Archives des Maladies du Coeur et des Vaisseaux, 59, 805-816. 
van de Werf, F., Piessens, J., De Geest, H., and Kesteloot, $H$. (1976). Normalized first derivative of the left apexcardiogram in assessment of left ventricular function. American Fournal of Cardiology, 37, 1059-1064.

Vetter, W. R., Sullivan, R. W., and Hyatt, K. H. (1972). Assessment of quantitative apexcardiography. A noninvasive index of left ventricular function. American fournal of Cardiology, 29, 667-671.

Wayne, H. H. (1970). The apexcardiogram in ischemic heart disease. California Medicine, 116, 12-20.

Wesseling, K. H., and Van Vollenhoven, E. (1969). Cathetermanometer systems. A review and some measurement results. TNO Nieuws, 24, 603-610.

Willems, J. L. H. (1973). The Normal Apexcardiogram, pp. 1-305. Arscia, Brussels.

Willems, J. L. H. (1974). Computer determination of noninvasive measures of "myocardial contractility" from the apex cardiogram. In Proceedings First World Congress on Medical Information, pp. 687-692. North Holland, Amsterdam.
Willems, J. L. H., De Geest, H., and Kesteloot, H. (1971a). A new approach to the recording of low frequency precordial vibrations. Acta Cardiologica, 26, 263-276.

Willems, J. L. H., De Geest, H., and Kesteloot, H. (1971b). On the value of the apexcardiogram for timing intracardiac events. American fournal of Cardiology, 28, 59-66.

Willems, J. L. H., Kesteloot, H., and De Geest, H. (1972). Influence of acute hemodynamic changes on the apexcardiogram in dogs. American fournal of Cardiology, 29, 504-513.

Willems, J. L. H., Kyle, M. C., Pillsbury, H. C., III, and Fries, E. D. (1975). The first derivative of the apexcardiogram and systolic time intervals in the evaluation of myocardial contractility in man. American fournal of Cardiology, 36, 873-879.

Requests for reprints to $\mathrm{Dr}$ Jos L. Willems, Academic Hospital St Rafaël, Kapucijnenvoer 35, B-3000 Leuven, Belgium. 